\title{
Antenatal Corticosteroids: A Risk Factor for the Development of Chronic Disease
}

\author{
Elizabeth Asztalos \\ Department of Paediatrics, University of Toronto and The Centre for Mother, Infant, and Child Research, Sunnybrook Research \\ Institute, Sunnybrook Health Sciences Centre, 2075 Bayview Avenue, Toronto, ON, Canada M4N 3M5 \\ Correspondence should be addressed to Elizabeth Asztalos, elizabeth.asztalos@sunnybrook.ca
}

Received 20 November 2011; Revised 30 December 2011; Accepted 31 December 2011

Academic Editor: Simon C. Langley-Evans

Copyright () 2012 Elizabeth Asztalos. This is an open access article distributed under the Creative Commons Attribution License, which permits unrestricted use, distribution, and reproduction in any medium, provided the original work is properly cited.

Preterm birth remains a major health issue worldwide. Since the 1990s, women at risk for preterm birth received a single course of exogenous antenatal corticosteroids (ACSs) to facilitate fetal lung maturity. More recently, repeated or multiple courses of ACS have been supported to provide continued fetal maturity support for women with continued risk of preterm birth. However, exogenous ACS reduces birth weight which, in turn, is associated with adverse adult outcomes such as coronary heart disease, stroke, hypertension, and type 2 diabetes. The long-term effects of ACS exposure on HPA axis activity and neurological function are well documented in animal studies, and it appears that ACS, regardless of dose exposure, is capable of affecting fetal HPA axis development causing permanent changes in the HPA axis that persists through life and is manifested by chronic illness and behavioral changes. The challenge in human studies is to demonstrate whether an intervention such as ACS administration in pregnancy contributes to developmental programming and how this is manifested in later life.

\section{Introduction}

The "developmental origins of health and disease" (DOHaD) refers to a concept where exposure to environmental factors such as maternal nutrition, body composition, and stress hormone levels sends signals to a developing fetus that potentially influences the metabolic phenotype of the offspring and its risk of chronic diseases later in life [1-5]. This concept was originally developed to explain observations between the high rates of death due to coronary heart disease in areas of England and Wales with high neonatal mortality and proposed that intrauterine deprivation was an important mediator [6]. Further studies found an inverse relationship between birthweight and coronary heart disease [7]. The association of low birth weight and increased incidence of chronic illnesses of adulthood, such as heart disease, hypertension, type 2 diabetes, has been documented in numerous studies [8-12]. Low birth weight has been proposed as an indicator of an environmental adversity during fetal development and may suggest fetal processes or programming are in place. Two mechanistic hypotheses have been proposed to explain how fetal programming may arise: fetal malnutrition and fetal overexposure to glucocorticoids both of which may have effects either directly or indirectly upon the developing fetus. Exposure to excess glucocorticoids in utero acts to program the fetal hypothalamic-pituitary-adrenal (HPA) axis, permanently altering basal and stress-induced HPA axis activity and regulation in the offspring throughout life. Fetal exposure to excess glucocorticoids can occur via a number of mechanisms such as maternal stress during pregnancy and maternal treatment with synthetic glucocorticoids (sGC), more commonly known as antenatal corticosteroids (ACS).

This paper will focus on ACS and its effect on the developing HPA axis and building the case for the use of ACS as a risk factor for the development of chronic disease in the offspring.

\section{Development and Function of the Hypothalamic-Pituitary-Adrenal (HPA) Axis}

Activation of the HPA axis after exposure to a stressor is part of a normal adaptive response allowing the organism to respond to changes in its environment [13]. Stress results 
in activation of central neurocircuitry, which in turn signals the hypothalamus to produce and secrete corticotrophinreleasing hormone (CRH) and vasopressin (AVP). CRH and AVP lead to the release of adrenocorticotrophic hormone (ACTH) from the anterior pituitary which stimulates the production and secretion of glucocorticoids (GC), principally cortisol in humans. Cortisol binds the glucocorticoid receptors (GR) in multiple target tissues to maintain homeostasis following stress. Cortisol also binds to GR and mineralocorticoid receptors (MR) in the limbic regions (including hippocampus and prefrontal cortex) to modify behaviours and learning and memory. In addition, cortisol acts to feedback and decrease HPA function in a classic endocrine feedback loop. Tightly regulated feedback control of cortisol is critical as prolonged tissue exposure to GC leads to metabolic and behavioural disorders [14]. The timing of maturation of the HPA axis relative to birth is highly speciesspecific and is linked to landmarks of brain development. In humans, like animals that give birth to mature young (primates, sheep, and guinea pigs), maximal brain growth and a large proportion of neuroendocrine maturation takes place in utero $[15,16]$.

\section{Role of $11 \beta$-HSD-2}

Low levels of GC are critical for normal fetal development; however, fetal exposure to elevated glucocorticoids can inhibit growth and adversely impact brain development. Under normal conditions, access of maternal cortisol to the fetus is low due to the placental expression of the enzyme, $11 \beta$-hydroxysteroid dehydrogenase-2 (11 $\beta$-HSD-2) [17]. Placental $11 \beta$-HSD-2 transforms cortisol into its much less active 11-keto form, cortisone. This protective placental enzymatic barrier is very efficient, such that only $10-20 \%$ of maternal cortisol crosses the placenta and reaches the fetus. This $10-20 \%$ passage of active maternal GC to the fetus reflects an anatomical bypass of the enzyme, presumably adding to the provision of GC for normal key developmental processes in the fetuses such as maturation of the lung and other fetal organs [18].

Low levels of placental $11 \beta$-HSD-2 activity have been correlated with low birth weight in humans and rodent models [19-22]. Reduced levels of $11 \beta$-HSD-2 may contribute to greater signaling within the placenta itself which may impact fetal development by altering placental function. Rodent studies have demonstrated that variations in placental $11 \beta$ HSD-2 levels have correlated with altered expression in glucose and amino acid transporter molecules as well as growth factors in the placenta [23].

It is clear that placental $11 \beta$-HSD-2 plays a key role in mediating the flow of environmental signals to the fetus. Animal studies have demonstrated that prenatal stress can lead to a reduction in placental $11 \beta$-HSD-2 activity suggesting then that the fetus and placenta are exposed to extra excessive amounts of GC [24]. In addition, dietary protein restriction selectively reduces $11 \beta$-HSD- 2 activity suggesting a common mechanism by which malnutrition and excess GC can programme adult biology $[25,26]$.
Unlike endogenous GC, the synthetic GCs utilized as ACS (dexamethasone and betamethasone) are poor substrates for $11 \beta$-HSD-2 and readily passes the placenta barrier. This lack of restriction allows ACS to exert its effect in the same manner as excessive endogenous GC.

\section{Other Stress-Related Programming Mediators}

While it is clearly evident the role GC has on influencing development under normal and stress-related circumstances, other substances are released by the mother and fetus in response to stress. Catecholamines, in particular adrenaline and noradrenaline, are of importance since they are both released by stress and may influence placental function and also transport across the placenta to the fetus [27]. However, more exploration in this area is required to determine how these catecholamines function in normal and abnormal situation and what contribution they may play in enhancing disease risk.

\section{Use of Antenatal Corticosteroids (ACSs) in the Management of Women at Risk for Preterm Birth}

Preterm delivery affects over $7-12 \%$ of births in North America alone and is responsible for up to $75 \%$ of neonatal deaths $[28,29]$. Despite advances in medical technology, the prevalence of preterm birth worldwide is increasing [29].

Respiratory distress syndrome, as a consequence of immature lung development, is a significant risk of preterm birth and the major cause of early neonatal mortality and morbidity [30]. Infants born very preterm (less than 32 weeks of gestation) often require respiratory support, in the form of positive pressure ventilation and prolonged oxygen support. A substantial proportion have intraventricular haemorrhages and associated "white matter brain injury" (grade 3 or 4 intraventricular haemorrhages, periventricular leukomalacia), bronchopulmonary dysplasia, and severe retinopathy of prematurity, all of which contribute significantly independently and combined to an adverse neurodevelopmental outcome in later life [31, 32]. Infants born preterm who survive have an increased risk of hospitalizations [33]. The personal and emotional costs for affected individuals and their families are high, as are the immediate and long-term monetary costs of these morbidities for parents and society [33]. Thus, preterm birth and preterm infants continue to remain a significant health issue worldwide.

The immature fetal lung is the target organ when women at risk of preterm birth are given ACS. Stimulation of the pulmonary surfactant system has been regarded as the most important effect of ACS. In addition, ACS can alter lung fluid absorption and alveolar development by inducing genes associated with the synthesis of surfactant proteins, fatty acid syntheses, the epithelial sodium channel, and the membrane protein sodium/potassium ATPase [34, 35]. The enhancement of these mechanisms causes an accelerated 
maturation of the fetal lung and reduces the severity of respiratory distress syndrome (RDS) in the first few days after a preterm birth. This, in turn, contributes to a reduction in mortality and other neonatal morbidities associated with preterm birth. In 1972, Liggins and Howie published the results of the first RCT evaluating the effects of a single course of ACS [36]. Among those women who had been in spontaneous preterm labour, ACS reduced the risk of respiratory distress syndrome (RDS) (9.0\% versus $25.8 \%$, $P=0.003)$ and early neonatal mortality (3.2\% versus $15.0 \%$, $P=0.01)$. Over the subsequent 20 years, 12 additional RCT, involving over 3000 infants, showed a benefit of a single course of ACS with no adverse effects [37].

Since the early 1990s, the recommendation has been that women, between 24 and 34 weeks of gestation and at high risk of preterm birth, receive a single course of ACS (2 doses of ACS 12 hours apart) [38, 39]. However, approximately $50 \%$ of women given a first course of ACS remain undelivered 7-14 days later, and, for these women, the question had arisen as to whether repeated courses of ACS should be given [40]. There has been no consensus on repeated courses of ACS in the management of women at risk for preterm birth [41]. In the past decade, 10 trials have been conducted to evaluate the risks and benefits of repeated courses of ACS to women at risk of preterm birth. The most recent review in the Cochrane Database of these trials involving over 4730 women and 5650 infants concludes that repeat courses of ACS does reduce the risk of RDS (risk ratio (RR) 0.83 , 95\% confidence interval (CI) 0.75-0.91), and serious infant outcomes (RR 0.84, 95\% CI 0.75-0.94) compared to no repeat ACS treatment [42]. However, these benefits were associated with a significant reduction in size at birth. Because of this reduction in size at birth, concern over the long-term effects in the offspring from repeated courses of ACS has been raised, and more research on the long-term effects has been recommended [43].

\section{Long-Term Clinical Significance of ACS Exposure in the Offspring}

Dalziel et al. reported on the cohort in the initial trial by Liggins and did not identify overt neurological and physiological effects of a single course of ACS in late gestation but did identify early markers of insulin resistance [44, 45]. Retrospective studies evaluating the effect of repeated courses on neonates and children have been somewhat conflicting; while they suggest benefit in terms of lung function in the neonatal period, there appears to be an increased risk of other outcomes, namely, long-term effects on behavior [46-49]. The 2-year followup of the recent RCT evaluating the use of repeated courses of ACS has reported no significant differences in the rate of deaths or major neurodevelopmental difficulties at 2 years of age [42, 50-54]. However, caution must be exercised because measurements at 2 years of age have limited predictive abilities and are only moderately correlated with developmental outcomes at later ages [55]. In addition, these outcome studies did not address the question of potential programming effect from ACS and impact on chronic illness development. Several ongoing studies are currently taking place to evaluate the children closer to school age which include the Canadian Institutes of Health Research (CIHR)- funded Multiple Antenatal Corticosteroids Study 5-year followup (MACS-5) and the 6year evaluation of the ACTORDS participants [56]. MACS-5 is specifically designed to evaluate the effect of ACS on the developing brain, specifically the hippocampus, by assessing memory, attention, and behaviour as well as neurocognitive abilities; the ACTORDS study has focused on neurocognition in addition to other developmental abilities as well as early biomarkers for chronic illness [56].

\section{Potential Effects of ACS during Pregnancy}

Much of what is known about the effect of ACS on various structures is from animal studies.

7.1. Brain Development. Endogenous GC is important for normal development of the central nervous system; circulating levels of GC are maintained at very low levels throughout the majority of gestation $[57,58]$. However, levels will change to meet the needs of the developing brain during "critical windows." Studies have shown that $11 \beta$-HSD- 2 in the fetal human brain is silenced between 19 and 26 weeks which would lead to localized increases in GC signaling $[59,60]$. GC is necessary for neuronal maturation, remodeling of axons and dendrite and cell survival [61, 62]. However, sustained elevation or depletion of GC during these "critical windows" of fetal development can modify brain structure with significant consequences to future function $[63,64]$. Prenatal GC administration has been shown to retard brain weight at birth in sheep [65], as well as delay maturation of neurons, myelination, glia, and vasculature [60]. It has been shown to have widespread effect on neuronal structure and synapse formation and altered hippocampal structure and volume which can affect memory and attention [60, 65-68].

The hippocampus highly expresses GR and MR and, as such, is vulnerable to high sustained levels of GC. Rodent models show that prenatal stress decreases synaptic spine density and neurogenesis which correlates with deficits in cognition and learning. Similar effects are seen in primates (baboons and rhesus monkeys) where exposure to dexamethasone or betamethasone leads to reduced levels of neuritogenesis and neuronal plasticity and pronounced degeneration of areas within the hippocampus. These effects were dose associated suggesting multiple exposures induced more severe damage that a single injection [68-72].

7.2. HPA Axis. A number of animal models have shown that maternal administration of sGC during pregnancy has profound acute and long-term effects on the developing HPA axis. The fetal brain contains high levels of GR over the 2nd and 3rd trimesters, with highest levels in the limbic system (which includes prefrontal cortex, hippocampus and amygdala), the hypothalamus paraventricular nucleus (PVN; source of $\mathrm{CRH}$ and AVP), and the anterior pituitary (site of ACTH production) [73]. Exposure of these structures 
to high levels of GC can lead to permanent programming of the function of these structures. This "programming" takes place via modification of both the GR and MR levels in the hippocampus, hypothalamus, and pituitary gland. Prenatal exposure to sGC leads to permanent changes in the expression of GRs and MRs in these structures resulting in altered negative feedback sensitivity and altered set points for HPA function. Long-term changes in the regulation of HPA function can predispose to chronic cardiometabolic and neurological disorders. In addition, imbalance of GR and MR in the limbic system can have profound effects on behaviours, including learning and attention [74].

The effects of sGC are also noted to be sex dependent $[75,76]$. Administration of a single course of sGC in a guinea pig model in a dose and regimen comparable to that used in humans demonstrated significantly increased levels of MR and GR in the brains of female-exposed guinea pigs. Multiple course exposure to sGC in the same model resulted in dosedependent reductions in hippocampal NMDA-receptors in the hippocampus and modification of hippocampal longterm potentiation (LTP; the biological substrate of learning and memory), in female but not male offspring $[77,78]$.

Limited studies have been undertaken to establish the long-term effects of fetal exposure to sGC on the HPA axis function in nonhuman primates. Uno et al. [79] and de Vries et al. [80] were both able to demonstrate that repeated exposure to sGC in rhesus monkeys and Vervet monkeys resulted in offspring demonstrating elevated cortisol levels and altered responses to stress throughout life.

\section{Mechanisms of Programming for ACS}

A key aspect of the $\mathrm{DOHaD}$ hypothesis is that the effects of the environment are mediated by physiological and metabolic effects during fetal and early postnatal life [15]. The HPA axis is a central mediator of the programming process. Prenatal stress leads to numerous cardiovascular and endocrine changes in the mother, including increases in plasma ACTH, $\beta$-endorphin, cortisol, and catecholamine concentrations. Although the placenta acts as a barrier to many of these maternal factors, a number will still pass to the fetus because of potential attenuation of $11-\beta-\mathrm{HSD}-$ 2 in noncritical windows. There may be activation of the fetal sympathetic nervous system which will contribute to programming of the HPA axis and lead to an altered physiological response in the fetus. Administration of ACS can be seen as mimicking "prenatal stress." Its effects are more direct as it is able to bypass the functional barrier of placental $11-\beta$-HSD-2 and bind directly to the GR and MR in the vulnerable regions of the hippocampus and alter HPA axis activity. ACS has been shown from the clinical trials to affect in utero weight gain and lead to a reduced birth weight [42], a surrogate crude measure which has been associated with the development of hypertension, type 2 diabetes, and cardiovascular disease in adulthood [81].

8.1. Role of Epigenetics. There is evidence that the early environment can permanently influence the genome through epigenetic mechanisms and in this way modifies endocrine function, metabolism, and behaviour of offspring [82-87]. Gene expression can be epigenetically modified through alterations in DNA methylation and chromatin structure (i.e., histone acetylation). DNA methylation is a process where a methyl group is covalently linked to cytosine [88]. Methylation patterns are established during early embryonic development and maintained by DNA methyltransferases [84]. In general, DNA methylation in regulatory regions (e.g., promoters) reduces gene expression and represents an important mechanism for tissue-specific gene silencing [89]. In contrast, demethylation leads to gene activation [88]. When methylation occurs in a gene promoter, the methyl group can interfere with transcription factor binding. Alternatively, gene silencing may occur through targeting of DNA-binding proteins. MeCP-1 and MeCP-2 (methyl cytosine binding proteins 1 and 2) recognize methylated DNA and recruit corepressors and histone modifying enzymes such as histone deacetylases and histone methyltransferases to methylated genes, precipitating an inactive chromatin configuration [88]. Important to this proposal, key genes that regulate HPA function (GR, CRH, POMC, and $11 \beta-\mathrm{HSD}$ 2 ) have been shown to be epigenetically regulated $[82,89-$ 93]. Altered gene promoter methylation has been identified in human diseases [90]. More recently, altered hippocampal GR promoter methylation patterns has been demonstrated in human suicide subjects [94]. Maternal stress/anxiety and dietary protein restriction during pregnancy $[92,93,95-98]$ and altered levels of maternal care $[82,85,99]$ can leave permanent epigenetic marks in the genome and result in stable life-long changes in gene expression in offspring. Szyf and Meaney have shown that increased maternal care in rats leads to demethylation and increased histone acetylation of the hippocampal GR promoter, which is maintained throughout life [82]. Importantly, this effect is genepromoter specific; other nonhippocampal GR promoters are not affected. Demethylation was specific to the NGFIA binding site in the $G R$ promoter, resulting in increased NGFI-A binding and increased GR expression. This leads to increased glucocorticoid feedback and a decrease in HPA activity [82]. The reduced promoter methylation could be reversed in adulthood by central infusion of L-methionine (a methyl donor) [86]. In other studies, protein restriction during rat pregnancy has been shown to cause reduced methylation of specific hepatic gene promoters, including the $G R$, and a resultant increase in gene transcription in $\mathrm{F}_{1}$ offspring. Again, this demethylation is gene-specific and can be prevented by folate (a methyl donor) supplementation during pregnancy [97]. Very recent rat and human studies have shown that maternal stress/anxiety during pregnancy leads to altered methylation of the hypothalamic $C R H$ promoter (rat offspring) and GR promoter in umbilical cord blood mononuclear cells (humans) [92, 93]. However, of most importance, glucocorticoids have been shown to cause permanent demethylation of specific fetal hepatic gene promoters in late gestation [100]. This demethylation results in enhanced transcription factor binding, and this is maintained following glucocorticoid withdrawal indicating stability of the effect [100]. One route by which sGC may 
modulate methylation status is through a reduction in folate availability. In this regard, Cushing's patients (with elevated plasma cortisol) exhibit hyperhomocysteinemia [101]. Hyperhomocysteinemia inhibits the activity of DNA methyltransferases and induces hypomethylation [102]. There is extremely strong evidence emerging indicating that fetal GC exposure, be it endogenous or exogenous in the form of ACS, has profound influences on the fetal epigenome.

8.2. Transgenerational Effects. Recent studies have begun to show that the effect of ACS exposure may not be restricted to the immediate offspring of the pregnancy at risk but may affect subsequent generations; this is known as "transgenerational effects". These effects have been observed in the rat model where the offspring of an $F_{1}$ progeny whose mothers were treated with dexamethasone in the final week of pregnancy were mated with males from the same prenatal treatment. Both the $\mathrm{F}_{1}$ and $\mathrm{F}_{2}$ generation offspring exhibited decreased weight at birth compared to controls and also demonstrated abnormal endocrine responses to glucose challenges [103]. The programming effects were transmitted by either maternal or paternal lines implying an epigenetic mechanism. Further studies are needed to elucidate these mechanisms and how this will translate into the clinical realm.

\section{The Need for Focused Research on Long-Term Effects of ACS}

Pregnant women at risk of preterm birth continue to be a major clinical obstetrical issue. A single course of ACS remains the standard of care in this clinical setting to optimize fetal lung maturity. Because of concerns of fetal growth alterations and potential neurodevelopmental impairments, systematic repetitive administration of ACS has not been adopted as standard care. However, because of the short-term benefits of reducing neonatal morbidity, the more recent Cochrane Review supports the use of this approach in identified high-risk women [42]. In addition, the concept of "rescue" ACS has emerged in which ACS is given again only when delivery has again become likely [104]. Recent data from two randomized trials demonstrate benefits in reducing acute neonatal pulmonary morbidity without noticeable effects on fetal growth $[105,106]$.

The long-term effects of antenatal sGC exposure on HPA axis activity and neurological function is well documented in animal studies, and it appears that sGC, regardless of dose exposure, is capable of affecting fetal HPA axis development causing permanent changes in the HPA axis that persists through life and is manifested by chronic illness and behavioral changes. The previous long-term studies of ACS have focused only on major neurodevelopmental difficulties (cerebral palsy, blindness, deafness, and cognition) to the age of 2 years. However, the more recent animal studies suggest that the long-term effects of any exposure to sGC are more related to behaviour and the cardiometabolic factors contributing to chronic mental and physical illnesses, none of which have been adequately assessed in the majority of the long-term human follow-up studies. In retrospective studies, there is some suggestion of the behaviour changes seen with repeated exposure to sGC [46]. If early exposure affects hippocampal structure and alters function as the myriad of studies in animal models suggest, then there is likely to be an explosion of cognitive challenges, behavior disorders, and, perhaps, the risk of psychological disorders [107]. Similarly, if there is significant alteration in the HPA axis, then a generation of children and perhaps beyond are prone to develop the chronic illnesses of adulthood, such as heart disease, hypertension, type 2 diabetes.

The use of ACS, single or multiple courses, in the obstetric management of women at risk for preterm birth is likely not to diminish. Further studies are required on how to optimize the use of ACS in those women who remain undelivered 7 to 10 days after receiving an initial course of ACS. In addition, it is critical to determine ACS role, regardless of dosage, in "fetal programming" and its potential impact on a generation of children as it relates to behaviour, learning skills, and the potential for chronic illness. If the impact can be identified, appropriate measures can be implemented to minimize its effect.

\section{References}

[1] P. P. Silveira, A. K. Portella, M. Z. Goldani, and M. A. Barbieri, "Developmental origins of health and disease (DOHaD)," Jornal de Pediatria, vol. 83, no. 6, pp. 494-504, 2007.

[2] R. A. Waterland and K. B. Michels, "Epigenetic epidemiology of the developmental origins hypothesis," Annual Review of Nutrition, vol. 27, pp. 363-388, 2007.

[3] P. D. Wadhwa, C. Buss, S. Entringer, and J. M. Swanson, "Developmental origins of health and disease: brief history of the approach and current focus on epigenetic mechanisms," Seminars in Reproductive Medicine, vol. 27, no. 5, pp. 358368, 2009.

[4] D. Barker, "Human growth and cardiovascular disease," Nestle Nutrition Workshop Series: Pediatric Program, vol. 61, pp. 21-33, 2008.

[5] D. J. P. Barker, "In utero programming of chronic disease," Clinical Science, vol. 95, no. 2, pp. 115-128, 1998.

[6] D. J. P. Barker and C. Osmond, "Infant mortality, childhood nutrition, and ischaemic heart disease in England and Wales," The Lancet, vol. 1, no. 8489, pp. 1077-1081, 1986.

[7] C. Osmond, D. J. P. Barker, P. D. Winter, C. H. D. Fall, and S. J. Simmonds, "Early growth and death from cardiovascular disease in women," British Medical Journal, vol. 307, no. 6918, pp. 1519-1524, 1993.

[8] D. J. P. Barker, C. N. Martyn, C. Osmond, C. N. Hales, and C. H. D. Fall, "Growth in utero and serum cholesterol concentrations in adult life," British Medical Journal, vol. 307, no. 6918, pp. 1524-1527, 1993.

[9] C. N. Hales, D. J. P. Barker, P. M. S. Clark et al., "Fetal and infant growth and impaired glucose tolerance at age 64," British Medical Journal, vol. 303, no. 6809, pp. 1019-1022, 1991.

[10] C. M. Law and A. W. Shiell, "Is blood pressure inversely related to birth weight? The strength of evidence from a systematic review of the literature," Journal of Hypertension, vol. 14, no. 8, pp. 935-941, 1996. 
[11] J. W. Rich-Edwards, M. J. Stampfer, J. E. Manson et al., "Birth weight and risk of cardiovascular disease in a cohort of women followed up since 1976," British Medical Journal, vol. 315, no. 7105, pp. 396-400, 1997.

[12] I. C. McMillen and J. S. Robinson, "Developmental origins of the metabolic syndrome: prediction, plasticity, and programming," Physiological Reviews, vol. 85, no. 2, pp. 571-633, 2005.

[13] R. M. Sapolsky, L. M. Romero, and A. U. Munck, "How do glucocorticoids influence stress responses? Integrating permissive, suppressive, stimulatory, and preparative actions," Endocrine Reviews, vol. 21, no. 1, pp. 55-89, 2000.

[14] E. Charmandari, T. Kino, E. Souvatzoglou, and G. P. Chrousos, "Pediatric stress: hormonal mediators and human development," Hormone Research, vol. 59, no. 4, pp. 161-179, 2003.

[15] J. Dobbing and J. Sands, "Comparative aspects of the brain growth spurt," Early Human Development, vol. 3, no. 1, pp. 79-83, 1979.

[16] S. G. Matthews, "Early programming of the hypothalamicpituitary-adrenal axis," Trends in Endocrinology \& Metabolism, vol. 13, pp. 373-380, 2002.

[17] J. R. Seckl, "Glucocorticoids, feto-placental $11 \beta$ hydroxysteroid dehydrogenase type 2 , and the early life origins of adult disease," Steroids, vol. 62, no. 1, pp. 89-94, 1997.

[18] M. Venihaki, A. Carrigan, P. Dikkes, and J. A. Majzoub, "Circadian rise in maternal glucocorticoid prevents pulmonary dysplasia in fetal mice with adrenal insufficiency," Proceedings of the National Academy of Sciences of the United States of America, vol. 97, no. 13, pp. 7336-7341, 2000.

[19] R. Benediktsson, A. A. Calder, C. R. W. Edwards, and J. R. Seckl, "Placental 11 $\beta$-hydroxysteroid dehydrogenase: a key regulator of fetal glucocorticoid exposure," Clinical Endocrinology, vol. 46, no. 2, pp. 161-166, 1997.

[20] R. W. Brown, R. Diaz, A. C. Robson et al., "The ontogeny of $11 \beta$-hydroxysteroid dehydrogenase type 2 and mineralocorticoid receptor gene expression reveal intricate control of glucocorticoid action in development," Endocrinology, vol. 137, no. 2, pp. 794-797, 1996.

[21] C. L. McTernan, N. Draper, H. Nicholson et al., "Reduced Placental $11 \beta$-Hydroxysteroid dehydrogenase type 2 mRNA levels in human pregnancies complicated by intrauterine growth restriction: an analysis of possible mechanisms," Journal of Clinical Endocrinology and Metabolism, vol. 86, no. 10, pp. 4979-4983, 2001.

[22] P. M. Stewart, F. M. Rogerson, and J. I. Mason, "Type $211 \beta$-hydroxysteroid dehydrogenase messenger ribonucleic acid and activity in human placenta and fetal membranes: its relationship to birth weight and putative role in fetal adrenal steroidogenesis," Journal of Clinical Endocrinology and Metabolism, vol. 80, no. 3, pp. 885-890, 1995.

[23] C. S. Wyrwoll, J. R. Seckl, and M. C. Holmes, "Altered placental function of $11 \beta$-hydroxysteroid dehydrogenase 2 knockout mice," Endocrinology, vol. 150, no. 3, pp. 12871293, 2009.

[24] J. Mairesse, J. Lesage, C. Breton et al., "Maternal stress alters endocrine function of the feto-placental unit in rats," American Journal of Physiology, vol. 292, no. 6, pp. E1526E1533, 2007.

[25] C. Bertram, A. R. Trowern, N. Copin, A. A. Jackson, and C. B. Whorwood, "The maternal diet during pregnancy programs altered expression of the glucocorticoid receptor and type 2 11 $\beta$-hydroxysteroid dehydrogenase: potential molecular mechanisms underlying the programming of hypertension in utero," Endocrinology, vol. 142, no. 7, pp. 2841-2853, 2001.

[26] S. C. Langley-Evans, D. S. Gardner, and A. A. Jackson, "Maternal protein restriction influences the programming of the rat hypothalamic-pituitary-adrenal axis," Journal of Nutrition, vol. 126, no. 6, pp. 1578-1585, 1996.

[27] S. Sarkar, S. W. Tsai, T. T. Nguyen, M. Plevyak, J. F. Padbury, and L. P. Rubin, "Inhibition of placental 11 $\beta$-hydroxysteroid dehydrogenase type 2 by catecholamines via $\alpha$-adrenergic signaling," American Journal of Physiology, vol. 281, no. 6 506, pp. R1966-R1974, 2001.

[28] Births 2007, "Statistics Canada," Ministry of Industry, Catalogue no. 84F0210X, Ottawa 2009.

[29] WHO (World Health Organization), "The world health report," 2005, http://www.who.int/whr/2005/en/index.html.

[30] M. S. Kramer, K. Demissie, H. Yang, R. W. Platt, R. Sauve, and R. Liston, "The contribution of mild and moderate preterm birth to infant mortality," Journal of the American Medical Association, vol. 284, no. 7, pp. 843-849, 2000.

[31] M. Hack and A. A. Fanaroff, "Outcomes of children of extremely low birthweight and gestational age in the 1990's," Early Human Development, vol. 53, no. 3, pp. 193-218, 1999.

[32] B. Schmidt, E. V. Asztalos, R. S. Roberts, C. M. T. Robertson, R. S. Sauve, and M. F. Whitfield, "Impact of bronchopulmonary dysplasia, brain injury, and severe retinopathy on the outcome of extremely low-birth-weight infants at 18 months," Journal of the American Medical Association, vol. 289, no. 9, pp. 1124-1129, 2003.

[33] S. Saigal and L. W. Doyle, "An overview of mortality and sequelae of preterm birth from infancy to adulthood," The Lancet, vol. 371, no. 9608, pp. 261-269, 2008.

[34] D. G. Grier and H. L. Halliday, "Effects of glucocorticoids on fetal and neonatal lung development," Treatments in Respiratory Medicine, vol. 3, no. 5, pp. 295-306, 2004.

[35] A. H. Jobe, "Glucocorticoids, inflammation and the perinatal lung," Seminars in Neonatology, vol. 6, no. 4, pp. 331-342, 2001.

[36] G. C. Liggins and R. N. Howie, "A controlled trial of antepartum glucocorticoid treatment for prevention of the respiratory distress syndrome in premature infants," Pediatrics, vol. 50, no. 4, pp. 515-525, 1972.

[37] P. Crowley, I. Chalmers, and M. J. N. C. Keirse, "The effects of corticosteroid administration before preterm delivery: an overview of the evidence from controlled trials," British Journal of Obstetrics and Gynaecology, vol. 97, no. 1, pp. 1125, 1990.

[38] National Institute of Child Health and Human Development Office of Medical Applications of Research, NIH, "Report of the Consensus Development Conference on the effect of corticosteroids for fetal maturation on perinatal outcomes," Vol. 95-3784, NIH Publication, November 1994.

[39] J. Crane, A. Armson, M. Brunner et al., "Antenatal corticosteroid therapy for fetal maturation," JOGC: Journal of Obstetrics and Gynaecology Canada, vol. 25, no. 1, pp. 45-52, 2003.

[40] K. J. McLaughlin, C. A. Crowther, N. Walker, and J. E. Harding, "Effects of a single course of corticosteroids given more than 7 days before birth: a systematic review," Australian and New Zealand Journal of Obstetrics and Gynaecology, vol. 43, no. 2, pp. 101-106, 2003. 
[41] Committee on Obstetric Practice, "ACOG committee opinion: antenatal corticoid therapy for fetal maturation," Obstetrics \& Gynecology, vol. 99, pp. 871-873, 2002.

[42] C. A. Crowther, C. J. McKinlay, P. Middleton, and J. E. Harding, "Repeat doses of prenatal corticosteroids for women at risk of preterm birth for improving neonatal health outcomes," Cochrane Database of Systematic Reviews (Online), no. 6, Article ID CD003935, 2011.

[43] O. M. Peltoniemi, M. A. Kari, and M. Hallman, "Repeated antenatal corticosteroid treatment: a systematic review and meta-analysis," Acta Obstetricia et Gynecologica Scandinavica, vol. 90, no. 7, pp. 719-727, 2011.

[44] S. R. Dalziel, V. K. Lim, A. Lambert et al., "Antenatal exposure to betamethasone: psychological functioning and health related quality of life 31 years after inclusion in randomised controlled trial," British Medical Journal, vol. 331, no. 7518, pp. 665-668, 2005.

[45] S. R. Dalziel, N. K. Walker, V. Parag et al., "Cardiovascular risk factors after antenatal exposure to betamethasone: 30Year follow-up of a randomised controlled trial," The Lancet, vol. 365, no. 9474, pp. 1856-1862, 2005.

[46] N. P. French, R. Hagan, S. F. Evans, M. Godfrey, and J. P. Newnham, "Repeated antenatal corticosteroids: size at birth and subsequent development," American Journal of Obstetrics and Gynecology, vol. 180, no. 1, pp. 114-121, 1999.

[47] J. A. Thorp, M. O'Connor, B. Belden, J. Etzenhouser, E. L. Hoffman, and P. G. Jones, "Effects of phenobarbital and multiple-dose corticosteroids on developmental outcome at age 7 years," Obstetrics and Gynecology, vol. 101, no. 2, pp. 363-373, 2003.

[48] N. P. French, R. Hagan, S. F. Evans, A. Mullan, and J. P. Newnham, "Repeated antenatal corticosteroids: effects on cerebral palsy and childhood behavior," American Journal of Obstetrics and Gynecology, vol. 190, no. 3, pp. 588-595, 2004.

[49] P. Kumar, R. Seshadri, and W. A. Grobman, "Neurodevelopmental outcome of very low birth weight infants after multiple courses of antenatal corticosteroids," Journal of the Society for Gynecologic Investigation, vol. 11, no. 7, pp. 483487, 2004.

[50] K. E. Murphy, M. E. Hannah, A. R. Willan et al., "Multiple courses of antenatal corticosteroids for preterm birth (MACS): a randomised controlled trial," The Lancet, vol. 372, no. 9656, pp. 2143-2151, 2008.

[51] C. A. Crowther, L. W. Doyle, R. R. Haslam, J. E. Hiller, J. E. Harding, and J. S. Robinson, "Outcomes at 2 years of age after repeat doses of antenatal corticosteroids," The New England Journal of Medicine, vol. 357, no. 12, pp. 1179-1189, 2007.

[52] R. J. Wapner, Y. Sorokin, L. Mele et al., "Long-term outcomes after repeat doses of antenatal corticosteroids," The New England Journal of Medicine, vol. 357, no. 12, pp. 1190-1198, 2007.

[53] O. M. Peltoniemi, M. A. Kari, A. Lano et al., "Two-year follow-up of a randomised trial with repeated antenatal betamethasone," Archives of Disease in Childhood, vol. 94, no. 6, pp. F402-F406, 2009.

[54] E. V. Asztalos, K. E. Murphy, M. E. Hannah et al., "Multiple courses of antenatal corticosteroids for preterm birth study: 2-Year outcomes," Pediatrics, vol. 126, no. 5, pp. e1045e1055, 2010

[55] M. Hack, H. G. Taylor, D. Drotar et al., "Poor predictive validity of the Bayley Scales of infant development for cognitive function of extremely low birth weight children at school age," Pediatrics, vol. 116, no. 2, pp. 333-341, 2005.
[56] C. A. Crowther, L. W. Doyle, P. Anderson et al., "Repeat dose(s) of prenatal corticosteroids for women at risk of preterm birth: early school-age outcomes (6 to-8 years) for the ACTORDS trial," E-PAS2011:3123.6.

[57] S. M. Korte, "Corticosteroids in relation to fear, anxiety and psychopathology," Neuroscience and Biobehavioral Reviews, vol. 25, no. 2, pp. 117-142, 2001.

[58] M. J. Meaney, J. Diorio, D. Francis et al., "Early environmental regulation of forebrain glucocorticoid receptor gene expression: implications for adrenocortical responses to stress," Developmental Neuroscience, vol. 18, no. 1-2, pp. 4972, 1996.

[59] M. H. Andrews and S. G. Matthews, "Regulation of glucocorticoid receptor mRNA and heat shock protein $70 \mathrm{mRNA}$ in the developing sheep brain," Brain Research, vol. 878, no. 1-2, pp. 174-182, 2000.

[60] S. G. Matthews, "Antenatal glucocorticoids and programming of the developing CNS," Pediatric Research, vol. 47, no. 3, pp. 291-300, 2000.

[61] R. W. Brown, K. E. Chapman, Y. Kotelevtsev et al., "Cloning and production of antisera to human placental 11 $\beta$ hydroxysteroid dehydrogenase type 2," Biochemical Journal, vol. 313, no. 3, pp. 1007-1017, 1996.

[62] P. M. Stewart, B. A. Murry, and J. I. Mason, "Type 2 $11 \beta$-hydroxysteroid dehydrogenase in human fetal tissues," Journal of Clinical Endocrinology and Metabolism, vol. 78, no. 6, pp. 1529-1532, 1994.

[63] J. R. Seckl, "Prenatal glucocorticoids and long-term programming," European Journal of Endocrinology, Supplement, vol. 151, no. 3, pp. U49-U62, 2004.

[64] M. Weinstock, "The long-term behavioural consequences of prenatal stress," Neuroscience and Biobehavioral Reviews, vol. 32, no. 6, pp. 1073-1086, 2008.

[65] W. L. Huang, L. D. Beazley, J. A. Quinlivan, S. F. Evans, J. P. Newnham, and S. A. Dunlop, "Effect of corticosteroids on brain growth in fetal sheep," Obstetrics and Gynecology, vol. 94, no. 2, pp. 213-218, 1999.

[66] W. L. Huang, C. G. Harper, S. F. Evans, J. P. Newnham, and S. A. Dunlop, "Repeated prenatal corticosteroid administration delays astrocyte and capillary tight junction maturation in fetal sheep," International Journal of Developmental Neuroscience, vol. 19, no. 5, pp. 487-493, 2001.

[67] W. L. Huang, C. G. Harper, S. F. Evans, J. P. Newnham, and S. A. Dunlop, "Repeated prenatal corticosteroid administration delays myelination of the corpus callosum in fetal sheep," International Journal of Developmental Neuroscience, vol. 19, no. 4, pp. 415-425, 2001.

[68] I. Antonow-Schlorke, M. Schwab, C. Li, and P. W. Nathanielsz, "Glucocorticoid exposure at the dose used clinically alters cytoskeletal proteins and presynaptic terminals in the fetal baboon brain," Journal of Physiology, vol. 547, no. 1, pp. 117-123, 2003.

[69] A. Hayashi, M. Nagaoka, K. Yamada, Y. Ichitani, Y. Miake, and N. Okado, "Maternal stress induces synaptic loss and developmental disabilities of offspring," International Journal of Developmental Neuroscience, vol. 16, no. 3-4, pp. 209-216, 1998.

[70] V. Lemaire, M. Koehl, M. Le Moal, and D. N. Abrous, "Prenatal stress produces learning deficits associated with an inhibition of neurogenesis in the hippocampus," Proceedings of the National Academy of Sciences of the United States of America, vol. 97, no. 20, pp. 11032-11037, 2000.

[71] H. Uno, L. Lohmiller, C. Thieme et al., "Brain damage induced by prenatal exposure to dexamethasone in fetal 
rhesus macaques. I. Hippocampus," Developmental Brain Research, vol. 53, no. 2, pp. 157-167, 1990.

[72] R. M. Sapolsky, H. Uno, C. S. Rebert, and C. E. Finch, "Hippocampal damage associated with prolonged glucocorticoid exposure in primates," Journal of Neuroscience, vol. 10, no. 9, pp. 2897-2902, 1990.

[73] A. Kapoor, S. Petropoulos, and S. G. Matthews, "Fetal programming of hypothalamic-pituitary-adrenal (HPA) axis function and behavior by synthetic glucocorticoids," Brain Research Reviews, vol. 57, no. 2, pp. 586-595, 2008.

[74] A. Harris and J. Seckl, "Glucocorticoids, prenatal stress and the programming of disease," Hormones and Behavior, vol. 59, pp. 279-289, 2010.

[75] M. Weinstock, E. Matlina, G. I. Maor, H. Rosen, and B. S. McEwen, "Prenatal stress selectivity alters the reactivity of the hypothalamic-pituitary adrenal system in the female rat," Brain Research, vol. 595, no. 2, pp. 195-200, 1992.

[76] C. M. McCormick, J. W. Smythe, S. Sharma, and M. J. Meaney, "Sex-specific effects of prenatal stress on hypothalamic-pituitary-adrenal responses to stress and brain glucocorticoid receptor density in adult rats," Developmental Brain Research, vol. 84, no. 1, pp. 55-61, 1995.

[77] D. Owen and S. G. Matthews, "Repeated maternal glucocorticoid treatment affects activity and hippocampal NMDA receptor expression in juvenile guinea pigs," Journal of Physiology, vol. 578, no. 1, pp. 249-257, 2007.

[78] E. Setiawan, M. F. Jackson, J. F. Macdonald, and S. G. Matthews, "Effects of repeated prenatal glucocorticoid exposure on long-term potentiation in the juvenile guinea-pig hippocampus," Journal of Physiology, vol. 581, no. 3, pp. 1033-1042, 2007.

[79] H. Uno, S. Eisele, A. Sakai et al., "Neurotoxicity of glucocorticoids in the primate brain," Hormones and Behavior, vol. 28, no. 4, pp. 336-348, 1994.

[80] A. de Vries, M. C. Holmes, A. Heijnis et al., "Prenatal dexamethasone exposure induces changes in nonhuman primate offspring cardiometabolic and hypothalamic-pituitaryadrenal axis function," Journal of Clinical Investigation, vol. 117, no. 4, pp. 1058-1067, 2007.

[81] S. G. Matthews, "Foetal experience: lifelong consequences," Journal of Neuroendocrinology, vol. 19, no. 1, pp. 73-74, 2007.

[82] I. C. G. Weaver, N. Cervoni, F. A. Champagne et al., "Epigenetic programming by maternal behavior," Nature Neuroscience, vol. 7, no. 8, pp. 847-854, 2004.

[83] I. C. G. Weaver, M. Szyf, and M. J. Meaney, "From maternal care to gene expression: DNA methylation and the maternal programming of stress responses," Endocrine Research, vol. 28 , no. 4 , p. $699,2002$.

[84] M. J. Meaney and M. Szyf, "Maternal care as a model for experience-dependent chromatin plasticity?" Trends in Neurosciences, vol. 28, no. 9, pp. 456-463, 2005.

[85] M. Szyf, I. C. G. Weaver, F. A. Champagne, J. Diorio, and M. J. Meaney, "Maternal programming of steroid receptor expression and phenotype through DNA methylation in the rat," Frontiers in Neuroendocrinology, vol. 26, no. 3-4, pp. 139-162, 2005.

[86] I. C. G. Weaver, F. A. Champagne, S. E. Brown et al., "Reversal of maternal programming of stress responses in adult offspring through methyl supplementation: altering epigenetic marking later in life," Journal of Neuroscience, vol. 25, no. 47, pp. 11045-11054, 2005.

[87] I. C. G. Weaver, J. Diorio, J. R. Seckl, M. Szyf, and M. J. Meaney, "Early environmental regulation of hippocampal glucocorticoid receptor gene expression: characterization of intracellular mediators and potential genomic target sites," Annals of the New York Academy of Sciences, vol. 1024, pp. 182-212, 2004.

[88] R. J. Klose and A. P. Bird, "Genomic DNA methylation: the mark and its mediators," Trends in Biochemical Sciences, vol. 31, no. 2, pp. 89-97, 2006.

[89] J. Newell-Price, "Proopiomelanocortin gene expression and DNA methylation: implications for Cushing's syndrome and beyond," Journal of Endocrinology, vol. 177, no. 3, pp. 365372, 2003.

[90] H. M. Abdolmaleky, K. H. Cheng, S. V. Faraone et al., "Hypomethylation of MB-COMT promoter is a major risk factor for schizophrenia and bipolar disorder," Human Molecular Genetics, vol. 15, no. 21, pp. 3132-3145, 2006.

[91] R. Alikhani-Koopaei, F. Fouladkou, F. J. Frey, and B. M. Frey, "Epigentic regulation of $11 \beta$-hydroxysteroid dehydrogenase type 2 expression," Journal of Clinical Investigation, vol. 114, no. 8, pp. 1146-1157, 2004.

[92] B. R. Mueller and T. L. Bale, "Sex-specific programming of offspring emotionality after stress early in pregnancy," Journal of Neuroscience, vol. 28, no. 36, pp. 9055-9065, 2008.

[93] T. F. Oberlander, J. Weinberg, M. Papsdorf, R. Grunau, S. Misri, and A. M. Devlin, "Prenatal exposure to maternal depression, neonatal methylation of human glucocorticoid receptor gene (NR3C1) and infant cortisol stress responses," Epigenetics, vol. 3, no. 2, pp. 97-106, 2008.

[94] P. O. McGowan, A. Sasaki, A. C. D’Alessio et al., "Epigenetic regulation of the glucocorticoid receptor in human brain associates with childhood abuse," Nature Neuroscience, vol. 12, no. 3, pp. 342-348, 2009.

[95] G. C. Burdge, M. A. Hanson, J. L. Slater-Jefferies, and K. A. Lillycrop, "Epigenetic regulation of transcription: a mechanism for inducing variations in phenotype (fetal programming) by differences in nutrition during early life?" British Journal of Nutrition, vol. 97, no. 6, pp. 1036-1046, 2007.

[96] G. C. Burdge, J. Slater-Jefferies, C. Torrens, E. S. Phillips, M. A. Hanson, and K. A. Lillycrop, "Dietary protein restriction of pregnant rats in the $\mathrm{F}_{0}$ generation induces altered methylation of hepatic gene promoters in the adult male offspring in the $\mathrm{F}_{1}$ and $\mathrm{F}_{2}$ generations," British Journal of Nutrition, vol. 97, no. 3, pp. 435-439, 2007.

[97] K. A. Lillycrop, E. S. Phillips, A. A. Jackson, M. A. Hanson, and G. C. Burdge, "Dietary protein restriction of pregnant rats induces and folic acid supplementation prevents epigenetic modification of hepatic gene expression in the offspring," Journal of Nutrition, vol. 135, no. 6, pp. 13821386, 2005.

[98] K. A. Lillycrop, J. L. Slater-Jefferies, M. A. Hanson, K. M. Godfrey, A. A. Jackson, and G. C. Burdge, "Induction of altered epigenetic regulation of the hepatic glucocorticoid receptor in the offspring of rats fed a proteinrestricted diet during pregnancy suggests that reduced DNA methyltransferase- 1 expression is involved in impaired DNA methylation and changes in histone modifications," British Journal of Nutrition, vol. 97, no. 6, pp. 1064-1073, 2007.

[99] F. A. Champagne, I. C. G. Weaver, J. Diorio, S. Dymov, M. Szyf, and M. J. Meaney, "Maternal care associated with methylation of the estrogen receptor- $\alpha 1 \mathrm{~b}$ promoter and estrogen receptor- $\alpha$ expression in the medial preoptic area of female offspring," Endocrinology, vol. 147, no. 6, pp. 29092915, 2006.

[100] H. Thomassin, M. Flavin, M. L. Espinas, and T Grange, "Glucocorticoid-induced DNA demethylation andgene 
memory during development," The EMBO Journal, vol. 20, pp. 1974-1983, 2001.

[101] M. Terzolo, B. Allasino, S. Bosio et al., "Hyperhomocysteinemia in patients with Cushing's syndrome," Journal of Clinical Endocrinology and Metabolism, vol. 89, no. 8, pp. 3745-3751, 2004.

[102] S. J. James, S. Melnyk, M. Pogribna, I. P. Pogribny, and M. A. Caudill, "Elevation in S-Adenosylhomocysteine and DNA hypomethylation: potential epigenetic mechanism for homocysteine-related pathology," Journal of Nutrition, vol. 132, no. 8, pp. 2361S-2366S, 2002.

[103] A. J. Drake, B. R. Walker, and J. R. Seckl, "Intergenerational consequences of fetal programming by in utero exposure to glucocorticoids in rats," American Journal of Physiology, vol. 288, no. 1, pp. R34-R38, 2005.

[104] T. Schmitz, "Antenatal corticosteroids: neonatal effects of a second course," Archives de Pediatrie, vol. 17, no. 3, pp. S101S104, 2010.

[105] O. M. Peltoniemi, M. A. Kari, O. Tammela et al., "Randomized trial of a single repeat dose of prenatal betamethasone treatment in imminent preterm birth," Pediatrics, vol. 119, no. 2, pp. 290-298, 2007.

[106] T. J. Garite, J. Kurtzman, K. Maurel, and R. Clark, "Impact of a "rescue course" of antenatal corticosteroids: a multicenter randomized placebo-controlled trial," American Journal of Obstetrics and Gynecology, vol. 200, no. 3, pp. 248.e1-248.e9, 2009.

[107] Y. I. Sheline, P. W. Wang, M. H. Gado, J. G. Csernansky, and M. W. Vannier, "Hippocampal atrophy in recurrent major depression," Proceedings of the National Academy of Sciences of the United States of America, vol. 93, no. 9, pp. 3908-3913, 1996. 


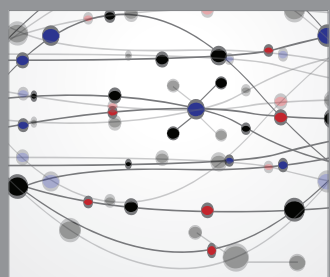

The Scientific World Journal
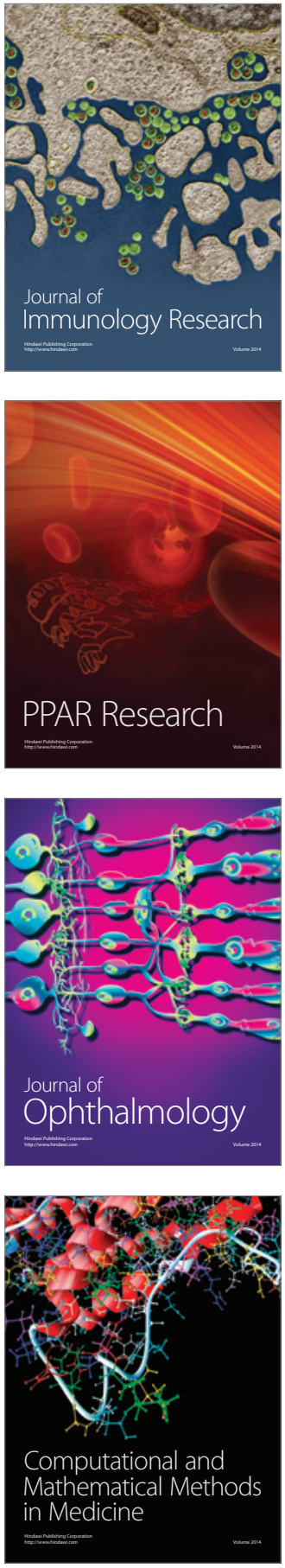

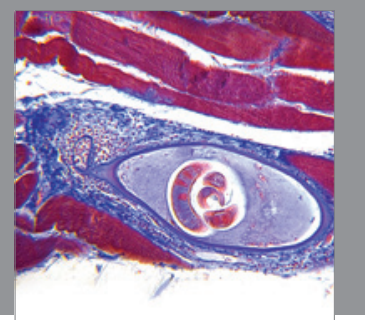

Gastroenterology

Research and Practice
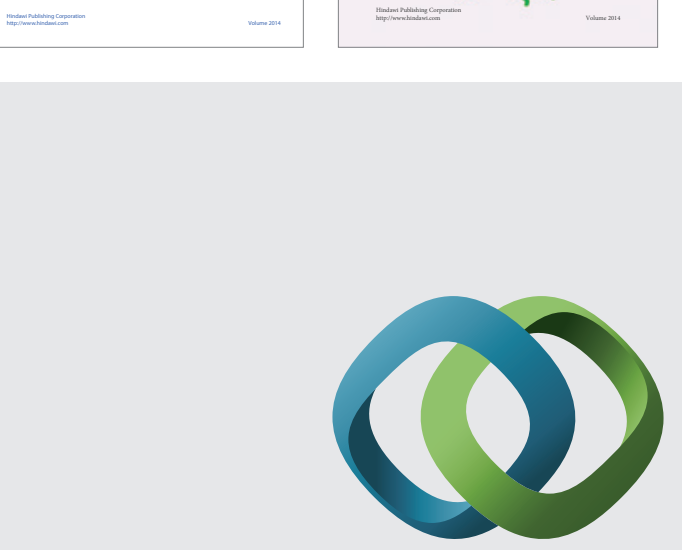

\section{Hindawi}

Submit your manuscripts at

http://www.hindawi.com
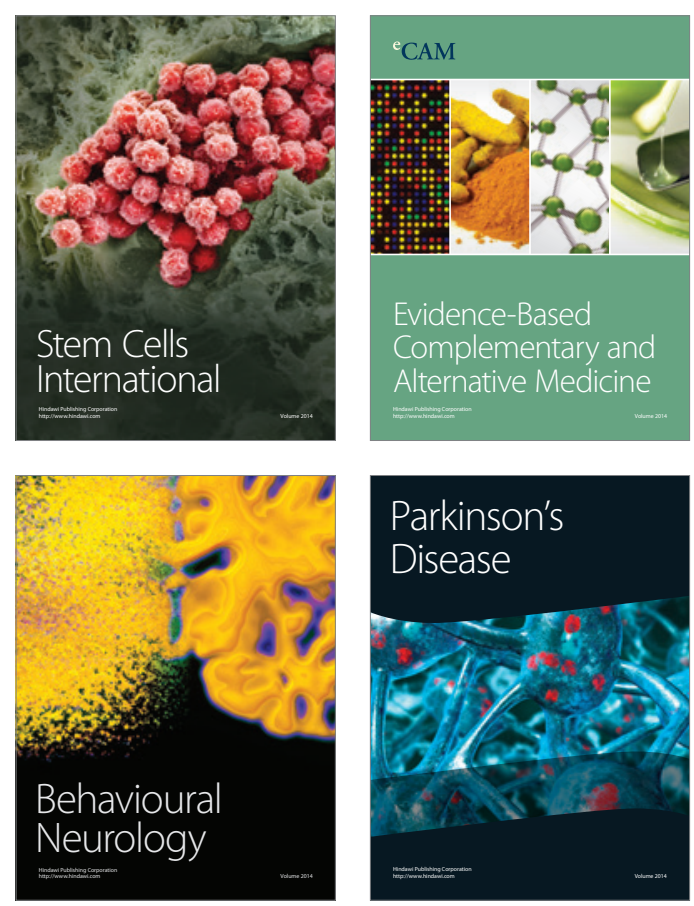

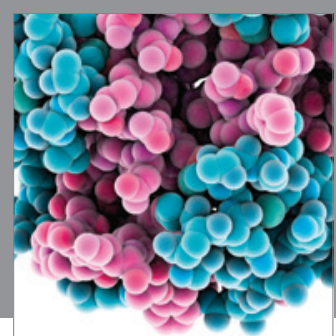

Journal of
Diabetes Research

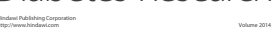

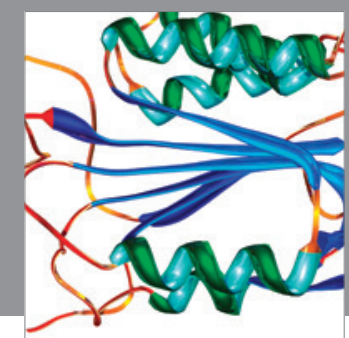

Disease Markers
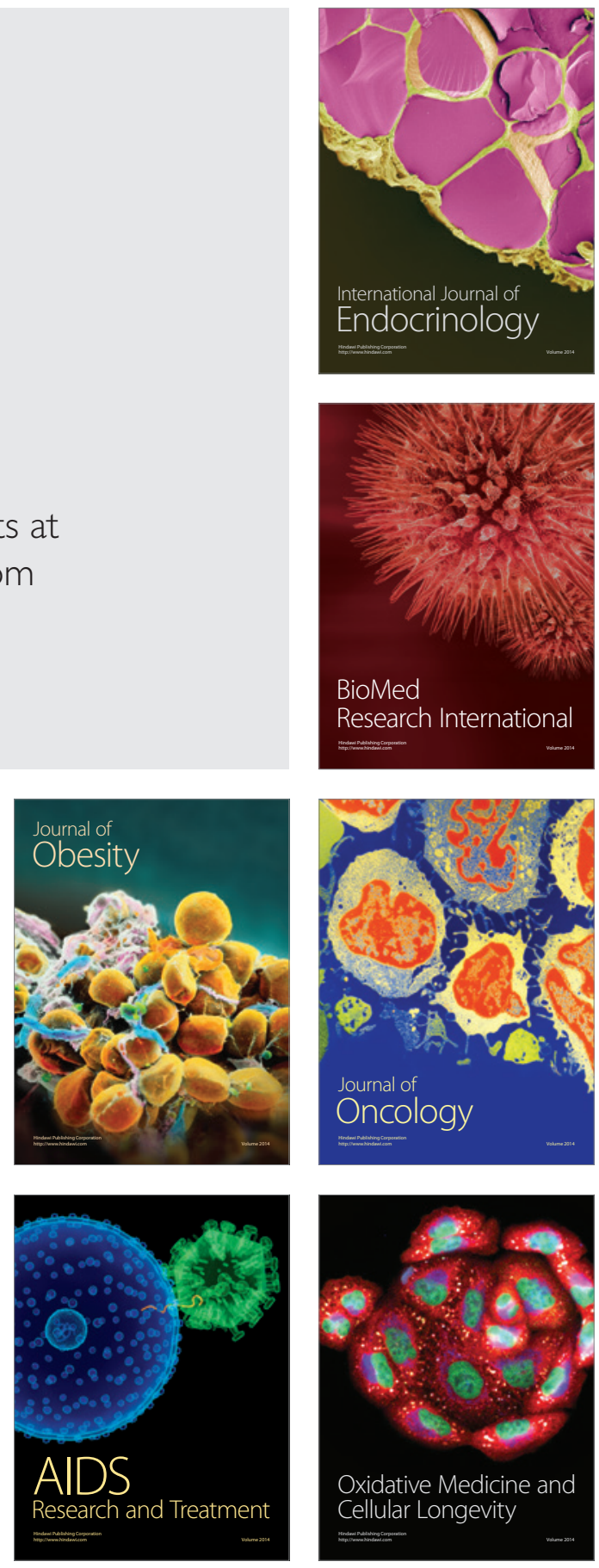